\title{
INACTIVATION OF NEURONAL FUNCTION IN THE AMYGDALOID REGION REDUCES TAIL ARTERY BLOOD FLOW ALERTING RESPONSES IN CONSCIOUS RATS
}

\author{
M. MOHAMMED, * K. KULASEKARA, ${ }^{\dagger}$ \\ R. C. DE MENEZES, ${ }^{\dagger}$. OOTSUKA AND W. W. BLESSING \\ Centre for Neuroscience, Department of Human Physiology, \\ Flinders University, Adelaide, SA, Australia
}

\begin{abstract}
Few studies have investigated whether neuronal function in the amygdaloid complex is necessary for the occurrence of the cardiovascular response to natural (unconditioned) environmental threats. In the present investigation in conscious unrestrained Sprague-Dawley rats we inactivated neuronal function in the amygdaloid complex acutely (bilateral muscimol injections) or chronically (unilateral or bilateral ibotenic acid injections) and measured the effect on sudden falls in tail artery blood flow elicited by non-noxious salient stimuli (sympathetic cutaneous vasomotor alerting responses, SCVARs). After acute bilateral injection of vehicle (200 $\mathrm{nl}$ Ringer's solution) the SCVAR index was $81 \pm 2 \%$, indicating that tail blood flow was reduced by $81 \%$ in response to the salient stimuli. After acute bilateral injection of muscimol $(1 \mathrm{nmol}$ in $200 \mathrm{nl}$ of Ringer's solution) into the amygdaloid complex the SCVAR index was $49 \pm 5 \%$, indicating that tail blood flow was reduced by $49 \%$ in response to the salient stimuli ( $p<0.01$ versus vehicle, $n=7$ rats for vehicle and 6 for muscimol). One week after unilateral ibotenic acid lesions, the SCVAR index was $68 \pm 3 \%$, significantly less than $90 \pm 1 \%$, the corresponding value after unilateral injection of vehicle ( $p<0.01, n=6$ rats in each group). After bilateral ibotenic acid lesions the SCVAR index was $52 \pm 4 \%$, significantly less than $93 \pm 1 \%$, the corresponding value after bilateral injection of vehicle $(p<0.001, n=6$ rats in each group). Ibotenic acid caused extensive neuronal destruction of the whole amygdaloid complex, as well as lateral temporal lobe structures including the piriform cortex. Our results demonstrate that the amygdaloid complex plays an important role in mediating the tail artery vasoconstriction that occurs in rats in response to the animal's perception of a salient stimulus, redirecting blood to areas of the body with more immediate metabolic requirements. (C) 2012 IBRO. Published by Elsevier Ltd. All rights reserved.
\end{abstract}

\footnotetext{
"Corresponding author. Tel: +61-8-8204-4107; fax: +61-8-82045768.

E-mail address: mazher.mohammed@flinders.edu.au (M. Mohammed).

† Present address: La Trobe Rural Health School, La Trobe University, P.O. Box 199, Bendigo, VIC 3552, Australia.

* Present address: Biological Sciences Department, Exact and Biological Sciences Institute, Federal University of Ouro Preto, 354000-000 Ouro Preto, MG, Brazil.

Abbreviations: ANOVA, analysis of variance; CV, coefficient of variation; SCVARs, sympathetic cutaneous vasomotor alerting responses.
}

Key words: amygdala, cutaneous blood flow, vasoconstriction, stress, ibotenic acid, muscimol.

\section{INTRODUCTION}

Relatively few studies have investigated the role of the amygdaloid complex in behavioral and autonomic responses to naturally occurring environmental events. Blanchard and Blanchard studied behavioral changes in rats with bilateral radiofrequency lesions of the amygdaloid complex (Blanchard and Blanchard, 1972; Kemble et al., 1984, 1990). The lesioned rats frequently approached a cat (sedated) introduced into the cage, and even climbed onto the cat. Blanchard and Blanchard concluded that the amygdala is involved in regulating the emotional-motivational state associated with defensive behaviors. Werka et al. (1978) showed that rats with lesions of the central nucleus of the amygdala readily cross an open field, rather than remain close to the wall. Fox and Sorenson (1994) also implicated the amygdala in natural fear responses, but contrasting findings have also been reported (Sananes and Campbell, 1989; Watkins et al., 1993). Generally similar behavioral changes were also observed in primates after amygdaloid lesions (Kluver and Bucy, 1939; Weiskrantz, 1956).

The studies cited above did not assess effects on autonomic cardiovascular variables. The amygdaloid complex has been shown to be part of the brain neural circuitry mediating cardiovascular responses to Pavlovian classically conditioned fear stimuli (LeDoux et al., 1986, 1988, 1990; LeDoux, 2000; Davis and Whalen, 2001; Gozzi et al., 2010; Pape, 2010; Pape and Pare, 2010). However only a few studies have documented the effect of amygdaloid lesions on autonomic cardiovascular responses to unconditioned stimuli (Galeno et al., 1984; Kubo et al., 2004; Fortaleza et al., 2009). Thus the role of amygdaloid nuclei in mediating cardiovascular responses to natural environmental threats is still largely undefined.

Thermoregulatory cutaneous vascular beds (ear pinna in rabbits and tail artery in rats) are extremely sensitive to the detection of significant, potentially threatening, environmental events, events that are salient for the life of the animal (Yu and Blessing, 1997a; de Menezes et al., 2009). When an animal detects such an event, the sympathetic outflow to the cutaneous beds is activated, causing a robust and substantial reduction in 
blood flow. In both rabbits and rats, these sudden falls in cutaneous blood flow are preceded by a sudden increase in the proportion of theta $(5-8 \mathrm{~Hz})$ rhythm in the hippocampal EEG, documenting that the animal has detected the salient environmental event ( $\mathrm{Yu}$ and Blessing, 1997a; de Menezes et al., 2009). We refer to the sudden reductions in cutaneous blood flow as SCVARs (sympathetic cutaneous vasomotor alerting responses) (Blessing, 2005; de Menezes et al., 2009). The associated increases in arterial blood pressure are quite modest, and the changes in heart rate vary with the nature of the stimulus (Galeno et al., 1984; Yu and Blessing, 1997a). Diversion of blood from the cutaneous bed may reduce the risk of hemorrhage in case of actual physical attack, and the blood can be redirected to areas of the body with more urgent metabolic requirements, including the brain ( $\mathrm{Yu}$ and Blessing, 1997b; Blessing, 2003).

In rabbits, functional inactivation of the amygdala by focal microinjections of either tetrodotoxin or the long acting GABA-A receptor agonist muscimol, substantially reduces SCVARs (Yu and Blessing, 1999, 2001). The present investigation was conducted to determine whether inactivation of the amygdaloid complex also reduces SCVARs in rats. We measured the tail artery blood flow response to salient stimuli in conscious rats after bilateral injection of muscimol into the amygdaloid complex, or after prior bilateral lesioning of neurons in the amygdaloid complex by focal microinjections of ibotenic acid.

\section{EXPERIMENTAL PROCEDURES}

\section{Animals and surgical procedures}

Experiments, approved by the Animal Welfare Ethics Committee of Flinders University, were carried out on 37 male SpragueDawley rats $(300-400 \mathrm{~g})$. Care was taken to minimize the number of animals. For implantation of measuring devices rats were anaesthetized with $2 \%$ isoflurane (Veterinary Companies of Australia Pty Ltd., NSW, Australia) in 100\% oxygen. An ultrasonic Doppler blood flow probe (lowa Doppler Products, IA, USA) was implanted around the tail artery about $2 \mathrm{~cm}$ distal to the base (Garcia et al., 2001; Ootsuka et al., 2009). After cannula implantation for amygdala injections (see below) flow probes were connected via subcutaneous wires to a headpiece attached to the skull.

\section{Preparation for acute injection of muscimol into the amygdaloid complex}

Anesthetized rats were placed in a stereotaxic apparatus (Stoelting Stereotaxic Instruments, USA) and via burr hole access, stainless steel guide cannula (26 gauge, Plastics One, Roanake, VA) were positioned bilaterally in the amygdaloid complex, $1 \mathrm{~mm}$ dorsal to the central nucleus (AP $-2.3 \mathrm{~mm}$; $\mathrm{ML}$ $+4.8 \mathrm{~mm}$; DV $7.0 \mathrm{~mm}$, Paxinos and Watson, 1986), a subnucleus of the amygdaloid complex containing neurons with major descending connections to hypothalamic and brainstem autonomic control centers (Sah et al., 2003).

The guide cannulae were held in place with stainless steel skull screws fixed to the skull and quick drying dental cement. Stainless steel stylets (33 gauge), with plastic caps, were inserted into the guide cannulae. The head socket for the tail probe wires was fixed to the skull using dental cement. All rats were treated post-operatively with analgesic (Caprofen, $5 \mathrm{mg} / \mathrm{kg}$ s.c., Norbrook Laboratories, Melbourne, Australia) and antibiotic (Baytril, $15 \mathrm{mg} / \mathrm{kg}$ s.c., Bayer Australia, Sydney, Australia). Animals recovered in the Animal House for at least 1 week.

On the day of the experiment the rat was transferred to a wooden box $\left(40 \times 40 \times 40 \mathrm{~cm}\right.$, temperature $\left.24-26^{\circ} \mathrm{C}\right)$ with a swivel device that could be connected by a flexible cable to the head socket. The tail artery Doppler blood flow signal was continually recorded for $30 \mathrm{~min}$ (see below) with the animal left undisturbed. The stylet was then removed from the guide cannula and replaced with an injection cannula (Hypotube S/S 304-RW stainless steel 33 gauge, Small Parts Inc., Miramar, FL, USA), with the ventral tip protruding $1 \mathrm{~mm}$ from the tip of the guide cannula. The proximal end of the injection cannula was already attached to plastic tubing (Polypropylene Dural Plastics \& Engineering, Auburn, NSW, Australia) connected to a calibrated $5-\mu \mathrm{l}$ glass micropipette (Clay Adams, Division of Becton, Dickinson and Company, Parsippany, NJ, USA). Either muscimol (Sigma, St. Louis, USA) or vehicle (ringer) was pressure injected using an air-filled syringe attached to the micropipette. Movement of a fluid-air meniscus in the micropipette was used to monitor the volume of the injection. Muscimol ( $1 \mathrm{nmol}$ in $200 \mathrm{nl}$ of ringer) or vehicle was injected bilaterally over a period of approximately $1 \mathrm{~min}$. The injection cannula was removed after an additional $1 \mathrm{~min}$, and replaced by the stylet.

The rat was then left undisturbed for $20 \mathrm{~min}$, and then a series of six standardized stimuli were administered (see below) and the effect on tail artery blood flow was recorded. The animal was then returned to the Animal House. Each rat received no more than two bilateral injections, one of muscimol and one of vehicle in counterbalanced order, with at least 2 days between injections. The injection sites for the first injection were marked by including fluorescent beads (FluoSpheres, Molecular Probes, OR, USA) in the injectate. The injection site for the second injection was marked by including a crystal of Horseradish Peroxidase (Sigma V1) dissolved in the injectate.

\section{Preparation of rats with chronic ibotenic acid lesions in the amygdaloid complex}

Rats were anesthetized and placed in the stereotaxic apparatus. Unilateral or bilateral burr holes were made in the skull. A small cut was made in the dura mater. A long-shanked $5-\mu$ glass micropipette (Accu-Fill 90, Micropet, Clay Adams, NJ, USA), calibrated in 100-nl steps, was filled with ibotenic acid solution (Tocris Bioscience, Bristol, UK) or vehicle and the position of a fluid-air meniscus in the micropipette was monitored. The tip of the micropipette was lowered into the basolateral amydgala (AP $-2.3 \mathrm{~mm}$; $\mathrm{ML}+4.8 \mathrm{~mm}$; DV $8.0 \mathrm{~mm}$ ) (Paxinos and Watson, 1986). Ibotenic acid (5 $\mu \mathrm{g}$ in $250 \mathrm{nl}$ ) or vehicle was injected during approximately $1 \mathrm{~min}$, and the pipette left in place for an additional $1 \mathrm{~min}$. The cannula was then withdrawn. The injection site was slightly more ventral than that used for the muscimol experiments. In preliminary studies we noted that ibotenic acid caused substantial necrosis so that axonal processes were damaged as well as perikarya, in more ventral and lateral portions of the temporal lobe, as well as in the amygdaloid complex. We chose the more ventral injection site for the ibotenic acid experiments to achieve more uniform destruction of both the ventral and lateral portions of the temporal lobe, including the piriform cortex, as well as the basolateral, centromedial and cortical groups of the amygdaloid complex as defined by Sah et al. (2003).

Further surgery for implantation of a Doppler flow probe around the base of the tail artery and a head-piece attached to the skull was performed, as described above. Animals were returned to the Animal House for at least 1 week before experimentation. 
On the day of the experiment, lesioned or control rats were transferred to the wooden box in the experimental room (as for muscimol experiments described above). The tail artery Doppler blood flow signal was continually recorded for $1 \mathrm{~h}$ with the animal left undisturbed. The standardized stimuli (see below) were then administered and the effect on tail artery blood flow recorded. Stimuli were administered at times when the tail artery blood flow was at a high level.

\section{Salient stimuli protocol}

In previous studies (Yu and Blessing, 1997a; de Menezes et al., 2009) we have demonstrated that environmental events that attract the animal's attention, and salient events as defined by a sudden increase in the power of hippocampal theta rhythm, also lead to a sudden fall in cutaneous blood flow. We have standardized a series of six stimuli, delivered in a constant order with at least $5 \mathrm{~min}$ between stimuli. These stimuli were used in the acute muscimol and chronic ibotenic acid experiments. (1) A flexible metal rod was released from a restraint so that it suddenly tapped the side of the wooden box. (2) $\mathrm{A} 0.5 \mathrm{~s}, 90 \mathrm{~dB}, 100 \mathrm{~Hz}$ sound was made outside the box. (3) The box was dropped $1.5 \mathrm{~cm}$ by a sudden removal of a support under the box. (4) The box was vigorously moved to and fro 2-3 times. (5) A small window $(15 \times 15 \mathrm{~cm})$ in the front of the box was suddenly opened. (6) The door of the box was opened and a single pinprick over the thigh was administered using a $23-\mathrm{G}$ sterile needle.

\section{Data recording and statistical analysis}

The tail artery Doppler signal was transmitted via the subcutaneous wires to the head piece and then, via a flexible cable and a swivel device to a System 6 Model 200 (Triton Technology, San Diego, USA) device that converted a frequency difference to a voltage. The voltage signal was calibrated in $\mathrm{cm} / \mathrm{s}$ using the Triton internal calibrator. The voltage signal was then transferred to a MacLab/s device programmed with Chart 7 software (ADinstruments Inc., Castle Hill, Australia) for signal sampling $(40 \mathrm{~Hz})$ and analog to digital conversion. The piezo-electric vibration sensor was also connected to the MacLab and sampled at $10 \mathrm{~Hz}$. Chart files were then exported to a Macintosh computer programmed with Chart and IgorPro software (Wavemetrics, Lake Oswego, USA).

In the acute muscimol or vehicle experiments the mean and the coefficient of variation ( $\mathrm{CV}$, expressed as a percentage) of the tail artery Doppler flow signal were calculated for the 20 -min control pre-injection period, and for the $20 \mathrm{~min}$ postinjection period (commencing $5 \mathrm{~min}$ after the injection). In the chronic ibotenic acid or vehicle experiments similar parameters were calculated for the 20-min undisturbed period before the administration of the first experimental stimulus (tap on the cage). In both the acute and chronic experimental models we quantified the change in the tail artery Doppler flow signal using the SCVAR index. We selected a 3-s signal sample just before administration of each of the six salient stimuli, and a poststimulus signal sample $(3 \mathrm{~s}$ sample at lowest flow level in the $10 \mathrm{~s}$ after the stimulus onset). The SCVAR index calculation uses both mean blood flow and the average amplitude of each individual tail artery pulse during the 3-s samples. The SCVAR index formula is 100-[(post-stimulus mean flow + post-stimulus mean pulse amplitude)/(pre-stimulus mean flow + pre-stimulus mean pulse amplitude) $* 100$ ], so that a large fall in the Doppler flow signal leads to a high SCVAR index. To simplify the presentation of results, in each experimental condition the separate indices for the six stimuli were averaged to provide a single SCVAR index value for each rat in each condition.

Group data are shown as mean \pm SEM unless otherwise indicated. Group results were analyzed statistically using Statview (SAS Institute, Carey, NC, USA) software. In the acute muscimol or vehicle injection experiments pre- and postinjection mean flow, CV and averaged SCVAR index values were compared using repeated measures analysis of variance (ANOVA). In the chronic model, effects of ibotenic acid versus vehicle were compared using factorial ANOVA. In addition, for SCVAR index values for each individual stimulus, we compared muscimol versus vehicle and bilateral ibotenic acid versus vehicle, using factorial ANOVA. Fischer's protected least significance difference test was used to determine significant post hoc differences between groups, with the primary analysis significance threshold set at 0.05 level.

\section{Histological examination of injection and lesion sites}

After completion of experiments using ibotenic acid injections, rats were anesthetized with pentobarbital $(100 \mathrm{mg} / \mathrm{kg}$ i.p.) and brains were perfused transcardially with aldehyde fixatives, removed and left in the fixative with $30 \%$ sucrose. Serial sections $(50 \mu \mathrm{m})$ were cut from the forebrain using a freezing microtome (Leitz) and stained for Nissl substance using Neutral Red. After muscimol treatment, the sections were processed for HRP reaction product, visualized with the diaminobenzidine (DAB, Sigma) reaction. The fluorescent beads were examined in an AX50 fluorescence microscope (Olympus).

\section{RESULTS}

\section{Bilateral muscimol injections into the amygdaloid complex}

Fig. 1 shows tail artery blood flow signals before and after bilateral injection of vehicle or muscimol into the amygdaloid complex. In the pre-injection signals, for both muscimol- and vehicle-injected rats, the tail artery blood flow signal shows frequent apparently spontaneous sudden falls to near zero levels, with gradual recovery to a high flow level. Muscimol injections substantially reduced these sudden falls, as is apparent in the group data for coefficient of variation (Table 1). Muscimol also increased the mean value of the tail flow signal (Table 1), principally because it substantially reduced the frequency of the sudden falls in flow. The combined stimuli SCVAR index results in Table 1 document that muscimol, but not vehicle, also substantially reduced the falls in tail artery blood flow elicited by experimental administration of the stimuli (Table 1). Fig. 4A shows that muscimol reduced the SCVAR index for each of the six individual stimuli, in comparison with vehicle-injected animals.

\section{Ibotenic acid injections into the amygdaloid complex}

Records from individual animals demonstrating the resting tail blood flow Doppler signal at least 1 week after bilateral ibotenic acid or vehicle injection are shown in Fig. 2 and expanded records of the SCVAR response to a tap stimulus after vehicle, unilateral or bilateral injections of ibotenic acid are shown in Fig. 3. Group results for unilateral and bilateral injections are shown in Table 2. The coefficient of variation of the tail flow signal and the overall SCVAR index (results for individual stimuli combined) were significantly reduced in comparison with vehicle-injected animals. The combined SCVAR index was lower after bilateral compared with unilateral injections. Fig. $4 \mathrm{~B}$ shows that bilateral 


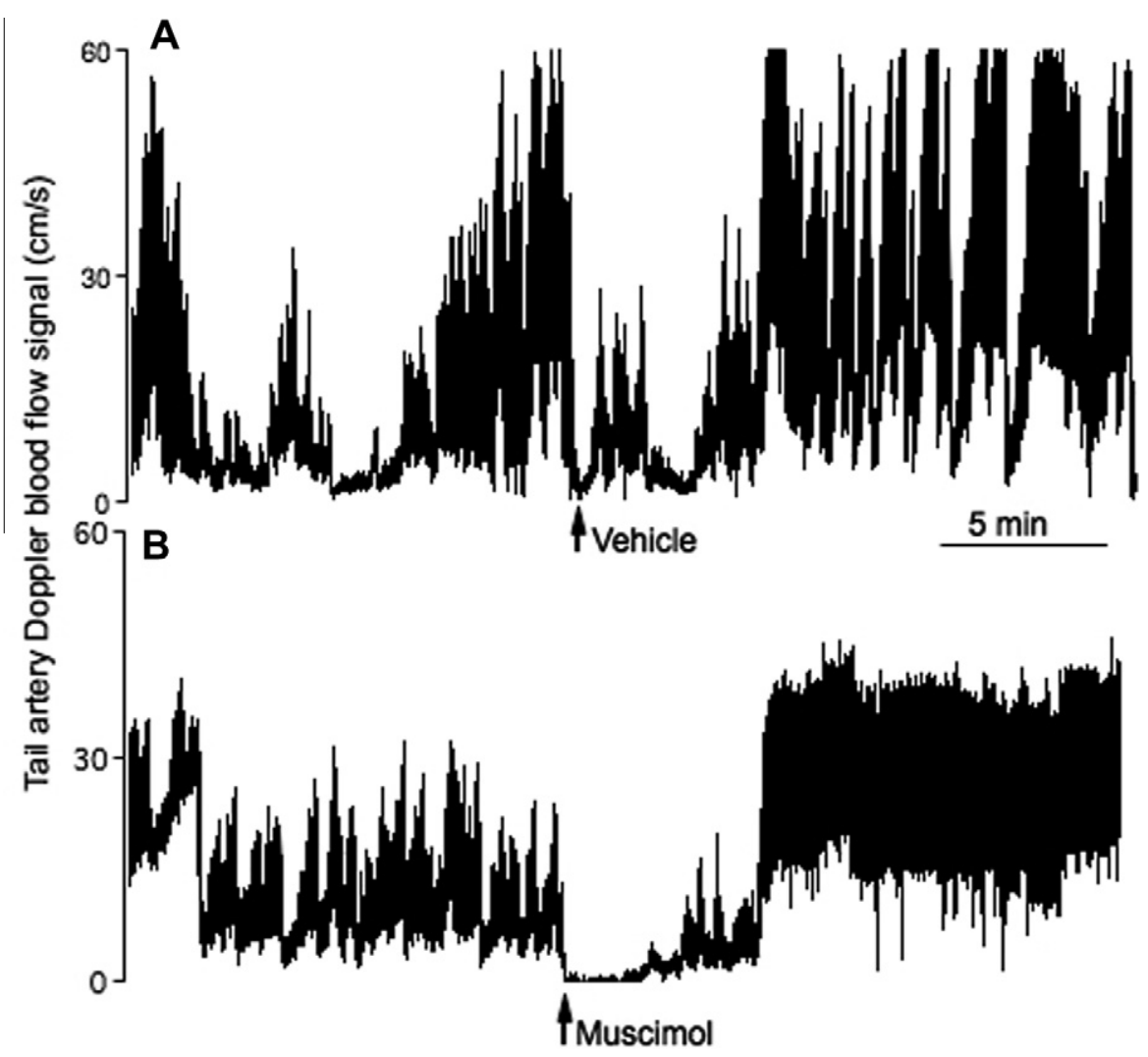

Fig. 1. Tail artery blood flow Doppler signals recorded approximately 30 min after the rat was transferred into the experimental cage. Either vehicle (A) or muscimol (B) was injected bilaterally into the amygdaloid complex, with the procedure commencing at the points marked by the small vertical arrows.

Table 1. Effects of bilateral injections of vehicle or muscimol into the amygdaloid complex in conscious freely moving rats

\begin{tabular}{lllllll}
\hline & \multicolumn{2}{l}{ Mean blood flow } & & \multicolumn{2}{l}{ Coefficient of variation } & \multirow{2}{*}{ SCVAR index after injection } \\
\cline { 2 - 3 } & Pre-injection & Post-injection & & Pre-injection & Post-injection & \\
\hline Vehicle & $11 \pm 2$ & $11 \pm 2 \mathrm{~ns}$ & & $88 \pm 11$ & $81 \pm 6 \mathrm{~ns}$ & $81 \pm 2$ \\
Muscimol & $9 \pm 2^{*}$ & $20 \pm 3^{*}$ & & $67 \pm 5^{*}$ & $46 \pm 4^{\bullet}$ & $49 \pm 5^{\S \S}$ \\
\hline
\end{tabular}

Grouped data (mean \pm SEM) for mean blood flow and coefficient of variation before and after injection, and the overall SCVAR index for combined stimuli after injection. *Not significantly different from vehicle pre-injection value; $\mathrm{ns}$, not significantly different from the corresponding pre-injection value, $p>0.05$. " ${ }^{\circ}$ Significantly different from the preinjection value, $p<0.01$. $\$$ Significantly different from the value after injection of vehicle, $p<0.01 ; n=7$ rats for vehicle and $n=6$ for muscimol.

injections of ibotenic acid substantially reduced the SCVAR responses to each of the six individual stimuli in comparison with vehicle-injected animals. After bilateral injections of ibotenic acid the SCVAR index was reduced to a value not significantly different from the corresponding value after bilateral injection of muscimol (Table 2).

\section{Histology}

Fig. 5 represents the histology of coronal sections of rat brains. Fig. 5A shows the bilateral guide cannulae tracts and the site of injections of muscimol. The HRP reaction product was found in basolateral, centromedial and cortical groups of the amygdaloid complex (Sah et al., 2003). Fluorescent beads were also injected to trace out the injection sites (Fig. 5B). Brain sections with ibotenic acid lesions were treated with neutral red for Nissl staining. Fig. $5 \mathrm{C}$ shows the effect of vehicle injection in the amygdaloid complex; in contrast Fig. 5D, represents the effect of ibotenic acid which clearly shows the substantial reduction in the visible cell nuclei in the basolateral, centromedial and cortical groups of the amygdaloid complex, as well as the ventrolateral portion of temporal lobe structures, including the piriform cortex.

\section{DISCUSSION}

\section{Cutaneous blood flow as an index of the perception of salient events}

Our previous publications have documented that sympathetic control of thermoregulatory cutaneous blood flow is exquisitely responsive to the perception of salient environmental events ( $\mathrm{Yu}$ and Blessing, 1997a; de Menezes et al., 2009). In the conscious rabbit (ear 


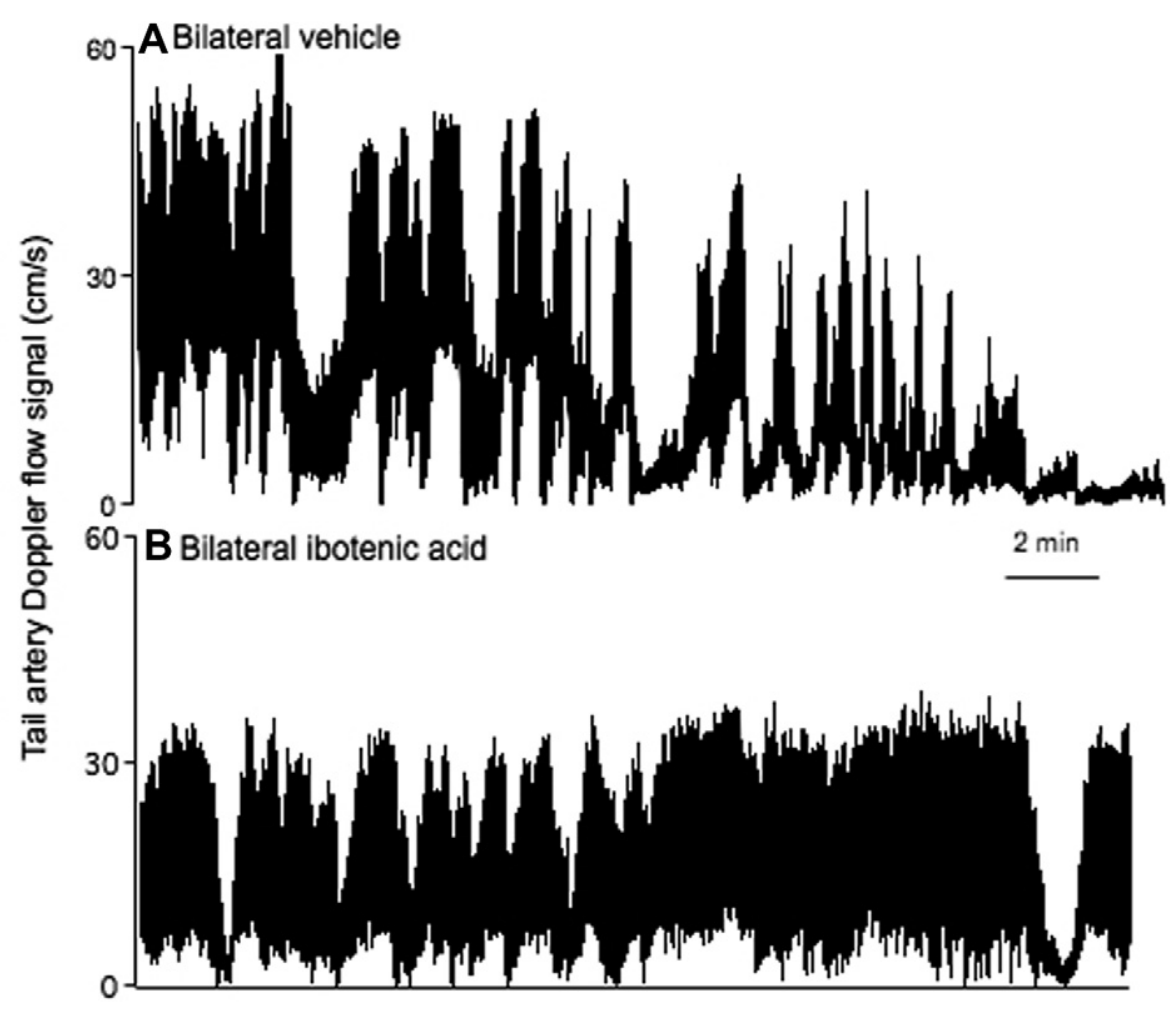

Fig. 2. Tail artery blood flow Doppler signals recorded approximately 1 week after bilateral injection of vehicle (A) or ibotenic acid (B) into the amygdaloid complex. Each record begins approximately $30 \mathrm{~min}$ after the rat was transferred to the experimental cage.

pinna blood flow) or rat (tail blood flow) cutaneous blood flow may suddenly fall to near zero levels either spontaneously or in response to apparently minor events, for example when the experimenter enters the room or when the laboratory telephone rings ( $\mathrm{Yu}$ and Blessing, 1997a). Thus the coefficient of variation of cutaneous blood flow is substantially greater than the variation of other cardiovascular parameters (including heart rate and arterial pressure), even in the absence of experimentally administered stimuli ( $\mathrm{Yu}$ and Blessing, 1997a, 1999, 2001). The substantial response of the cutaneous vascular bed to salient stimuli contrasts with relatively minor changes in arterial pressure and in blood flow to other vascular beds ( $\mathrm{Yu}$ and Blessing, 1997a). Even when the experimentally introduced stimulus is probably in the stressful range, for example a 110-db noise, changes in blood flow to non-cutaneous vascular beds are minor (Galeno et al., 1984; de Menezes et al., 2009).

Sudden falls in tail artery blood flow in rats, quantified by the SCVAR index, provide a sensitive measure of the animal's perception of salient environmental events. It is not essential for the event to be noxious or obviously stressful. Diversion of blood from the cutaneous beds could reduce the risk of hemorrhage in the case of actual physical attack, and increase the proportion of the cardiac output available for organs with increased metabolic requirements in emergency situations, including the brain (Yu and Blessing, 1997b; Blessing et al., 1998; Blessing, 2003). Diversion of blood from the cutaneous bed also occurs when the animal is actively exploring the environment, a situation in which the power of hippocampal theta rhythm also increases (Ootsuka et al., 2009; Blessing et al., 2012).

\section{The amygdaloid complex and cutaneous blood flow}

Our present study demonstrates that inactivation of neuronal function in basolateral, centromedial and cortical groups of the amygdaloid complex (Sah et al., 2003), substantially impairs SCVARs. After bilateral acute injections of muscimol and 1 week after bilateral ibotenic acid lesions, the SCVAR response was reduced by approximately $50 \%$. Chronic ibotenic acid lesions involving the same regions of the amygdala as well as the ventrolateral portion of temporal lobe structures, including the piriform cortex had a similar effect. There was no significant difference in the SCVAR index between muscimol and ibotenic treatments. Vehicle injections into the amygdaloid complex did not affect the SCVAR index. Our results support our previous demonstration of the importance of the amygdala in mediating the ear pinna blood flow response to salient stimuli in rabbits (Yu and Blessing, 1997a, 1999). Amygdaloid neural circuitry is very important in the regulation of vigilance and in the detection of potentially dangerous (salient) external environmental events (Wan and Swerdlow, 1997; Li et al., 2004; Herdade et al., 2006; Vinkers et al., 2010). Since cutaneous vasoconstriction is a prominent component of the unconditioned autonomic response to a salient event (Yu and Blessing, 1997a; de Menezes et al., 2009), this 


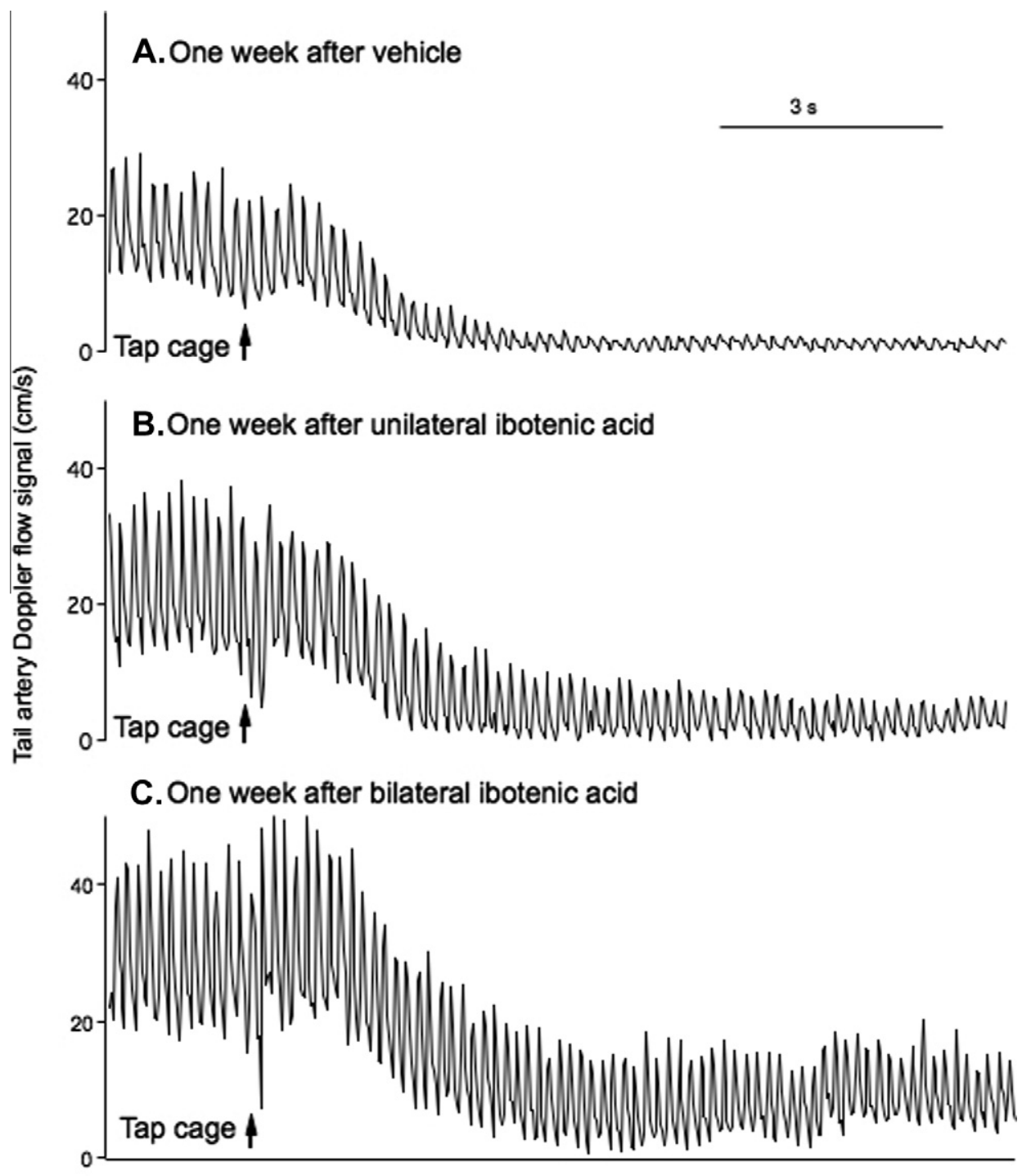

Fig. 3. Pulsatile tail artery blood flow signal recorded during a single tap (small vertical arrow) on the outside of the closed wooden box, at least 1 week after injection of (A) vehicle, or (B) unilateral ibotenic acid, or (C) bilateral ibotenic acid into the amygdaloid complex of three different rats.

Table 2. Effect of unilateral or bilateral injections of vehicle, unilateral ibotenic acid or bilateral ibotenic acid into the amygdaloid complex

\begin{tabular}{llll}
\hline & Mean blood flow & Coefficient of variation & SCVAR index (combined stimuli) \\
\hline Vehicle & $20 \pm 2$ & $79 \pm 3$ & $91 \pm 01$ \\
Unilateral Ibotenic acid & $22 \pm 3 \mathrm{~ns}$ & $61 \pm 6^{*}$ & $68 \pm 3^{\boldsymbol{*}}$ \\
Bilateral Ibotenic acid & $21 \pm 3 \mathrm{~ns}$ & $55 \pm 3^{\boldsymbol{*}}$ & $52 \pm 4^{\boldsymbol{*}, * *, \S}$ \\
\hline
\end{tabular}

Group results (mean \pm SEM) show the mean blood flow, the coefficient of variation and the overall SCVAR index for combined stimuli, recorded at least 1 week after the injections. ns, not significantly different from vehicle, $p>0.05$. "Significantly different from vehicle, $p<0.05$. "Significantly different from vehicle, $p<0.01$. ${ }^{* *}$ Significantly less than the SCVAR index after unilateral ibotenic acid, $p<0.01$. ${ }^{\S}$ Not significantly different from the SCVAR index after acute bilateral injection of muscimol (see muscimol result in Table 1). $n=12$ rats for vehicle and $n=6$ rats for unilateral ibotenic acid and $n=6$ rats for bilateral ibotenic acid.

particular autonomic response is substantially impaired by inactivation of amygdaloid function.

Many previous studies have documented the role of the amygdala in mediating behavioral and autonomic cardiovascular responses to conditioned stimuli (Iwata et al., 1987; LeDoux et al., 1988; LeDoux, 2000; Holahan and White, 2004). In addition, studies show that stressful stimuli, including restraint and air jet stress, increase the expression of Fos protein in the amygdaloid complex (Dayas et al., 1999; Dayas and Day, 2002). There are also many published studies demonstrating variable cardiovascular changes elicited by electrical or chemical stimulation of the amygdaloid complex (Hilton and Zbrozyna, 1963; Cox et al., 1987; Gelsema et al., 1987; Iwata et al., 1987; Brown and Gray, 1988). The amygdaloid complex is also prominent 


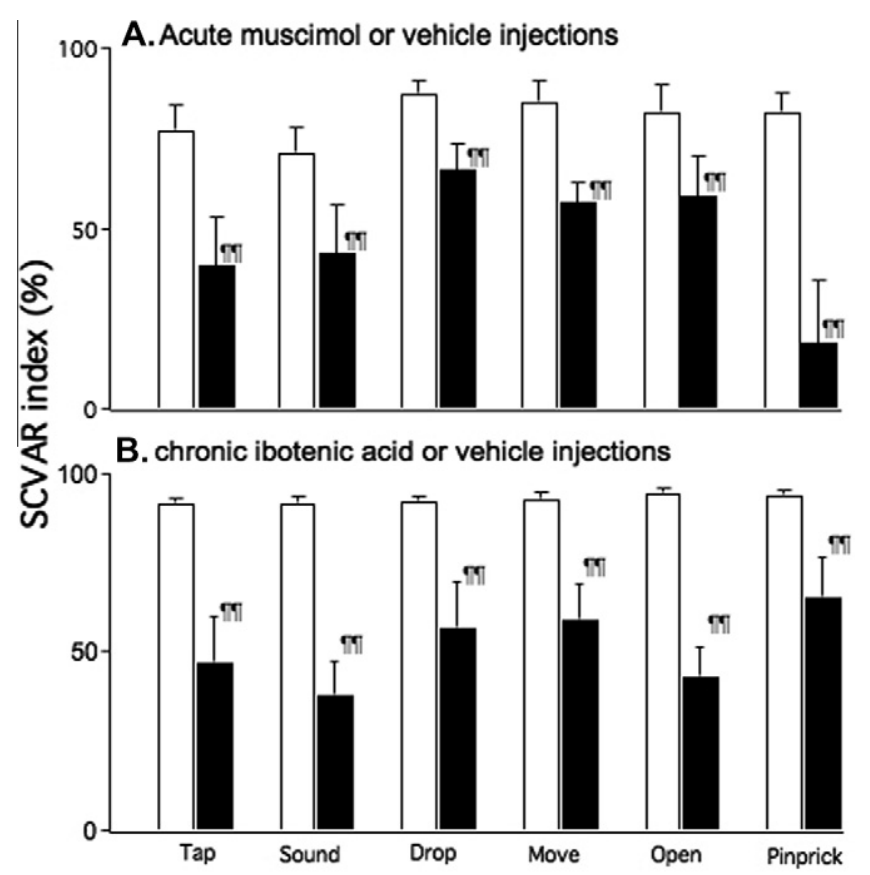

Fig. 4. Group data (mean \pm SEM) showing the SCVAR index produced by each of the series of six standardized salient stimuli. (A) After acute bilateral injection of vehicle (unfilled bars, $n=7$ rats) or muscimol (filled bars, $n=6$ rats). (B) One week after bilateral injections of vehicle (unfilled bars, $n=6$ rats) or ibotenic acid (filled bars, $n=6$ rats). ${ }^{\top} p<0.01$ versus vehicle.
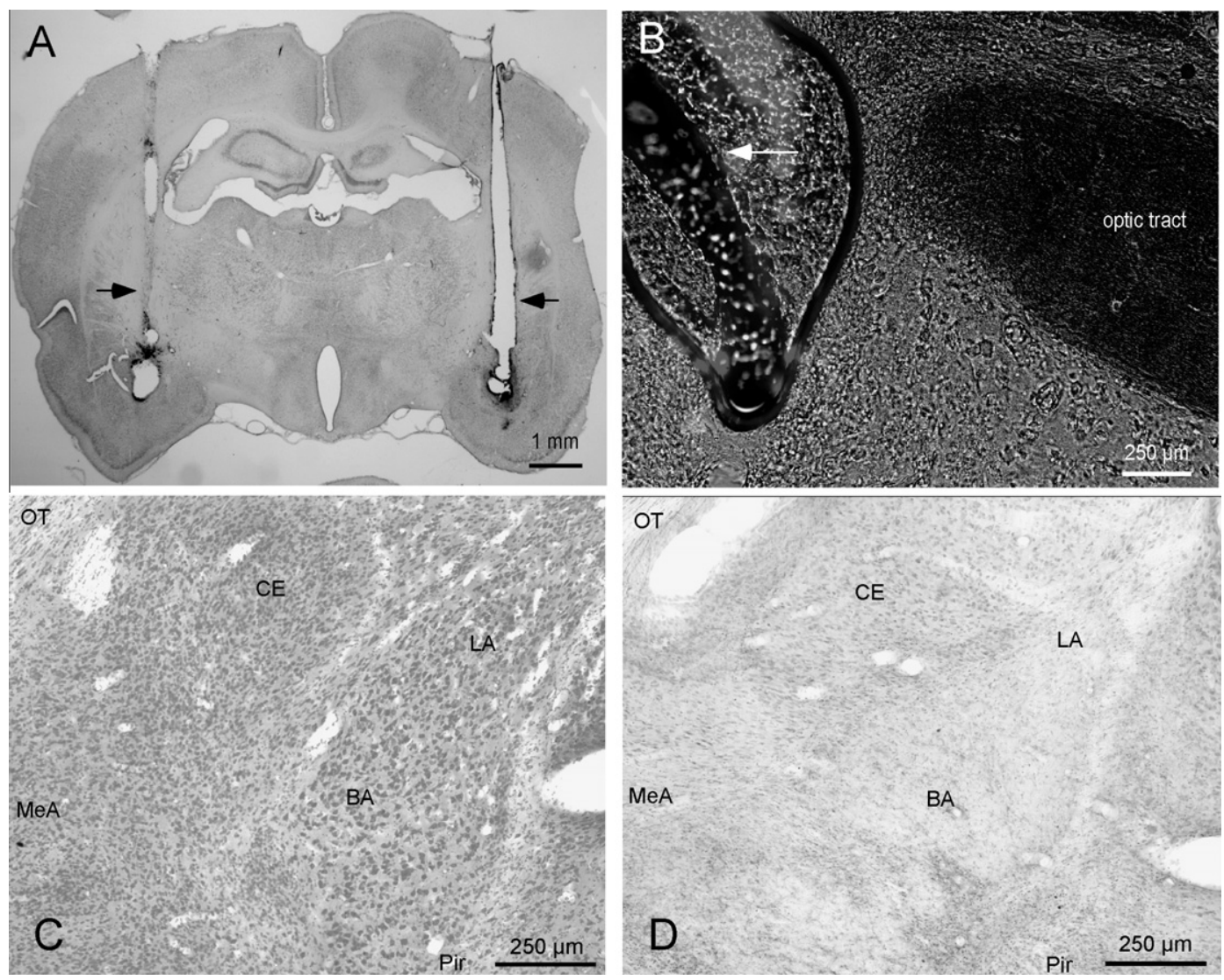

Fig. 5. Photographs taken from coronal sections of a rat brain after intra-amygdala injections of HRP with the muscimol solution (A) or fluorescent beads (B). Arrows in (A) indicate the tract made by the guide cannulae and arrows in (B) indicate the fluorescent beads at the injections site. (C) The effect of chronic vehicle injections and (D) the effect of ibotenic acid in the amygdaloid complex. OT, optic tract; CE, central nucleus of the amygdala; MeA, medial amygdala; LA, lateral amygdala; BA, basal amygdala; Pir, piriform cortex. 
in functional MRI studies involving anxiety and fear in humans (Adolphs et al., 1995; Phelps and LeDoux, 2005; Liao et al., 2010).

In contrast, there are relatively few published investigations providing direct evidence that functional inactivation of the amygdaloid complex substantially alters autonomic cardiovascular responses to unconditioned stimuli (loud noises, restraint). Galeno et al. (1984) reported reductions in the amplitude of stress-induced arterial blood pressure increases elicited by $110-\mathrm{db}$ noise after bilateral electrolytic lesions of the amygdala. Kubo et al. (2004) reported similar reductions in the amplitude of arterial blood pressure increases elicited by restraint stress after bilateral muscimol injections into the amygdala. On the other hand, Fortaleza and colleagues (2009) found that synaptic blockade in the medial amygdala had little or no effect on blood pressure and heart rate response to restraint stress. Other investigators have demonstrated that the hypothalamic-pituitary-adrenal axis response to stressful stimuli is reasonably normal after amygdaloid lesions (Carter et al., 2004), but the stress-induced hyperthermia response is reduced (Vinkers et al., 2010). Startle reactions were preserved after medial amygdaloid lesions (Kemble et al., 1984).

Our present study does not formally report behavioral indices in the ibotenic acid-lesioned rats. On simple visual inspection, the rats with chronic bilateral ibotenic acid lesions appeared to exhibit reasonably normal behaviors, but the animals were clearly more active than normal Sprague-Dawley rats. As an example, when transferred to a small plastic bucket on the weighing scale, the lesioned rats kept moving around, pushing up against the lid, so that it was difficult to obtain a steady reading.

The lesions resulting from the ibotenic acid injection were extensive, involving the whole amygdaloid region and, usually, the neighboring piriform cortex, but sparing the bed nucleus of the stria terminalis and the ventral hippocampus. When the muscimol injection sites were visualized using the HRP reaction product, the injected area included all the amygdaloid nuclei, but there was no spread to the piriform cortex. Neither the acute bilateral muscimol nor the chronic bilateral ibotenic acid procedure completely abolished the cutaneous blood flow response. Similarly, the cardiovascular response to conditioned fear stimuli is substantially reduced but not completely abolished by inactivation of amygdaloid function (LeDoux et al., 1986).

The descending neuroanatomical pathway for the amygdaloid-mediated response to conditioned fear includes the dorsomedial hypothalamus and the midbrain periaqueductal gray (LeDoux et al., 1988). The corresponding descending pathway for the natural unconditioned autonomic response to salient stimuli is not yet established, but the dorsomedial hypothalamic nucleus and the medullary raphe nuclei are likely to be involved (Nalivaiko and Blessing, 2001, 2002). The preservation of a degree of the vasoconstrictor response to salient stimuli after extensive inactivation of amygdaloid function emphasizes the importance of other forebrain pathways, including the medial prefrontal cortex, the ventral hippocampus and the bed nucleus of the stria terminalis (Radley and Sawchenko, 2011) in the mediation of autonomic responses to salient stimuli. Projections from the amygdala to the hypothalamus and lower brainstem are predominantly ipsilateral (Price and Amaral, 1981; Gray et al., 1989; Blessing et al., 1991), a factor that could contribute to the greater effect of bilateral compared to unilateral amygdaloid lesions.

Inactivation of amygdaloid function reduced the SCVAR index for all of the six salient stimuli, in both the acute and the chronic experiments, so that the tail vasoconstrictor response to the perception of a salient stimulus is not restricted to a particular sensory modality. In our previous study with bilateral muscimol inactivation of the amygdala in rabbits ( $Y u$ and Blessing, 2001), ear pinna vasoconstriction could still be elicited by application of a normally painful stimulus (forceful pinching of the ear pinna). Even in anesthetized rabbits, nociceptive stimulation vigorously reduces cutaneous blood flow, by a brain pathway that descends to the spinal cord via a synapse in the medullary raphe nuclei (Blessing et al., 1998; Blessing and Nalivaiko, 2000). The hypothalamic and/or brainstem neural circuity mediating the nociceptive cutaneous vasoconstrictor response might form part of the descending pathways for the cutaneous vasoconstrictor response to salient stimuli that is mediated by amygdaloid neural circuitry.

Acknowledgments-The authors thank Robyn Flook, Pam Simpson and Jessi Moore for their technical assistance.

\section{REFERENCES}

Adolphs R, Tranel D, Damasio H, Damasio AR (1995) Fear and the human amygdala. J Neurosci 15:5879-5891.

Blanchard DC, Blanchard RJ (1972) Innate and conditioned reactions to threat in rats with amygdaloid lesions. J Comp Physiol Psychol 81:281-290.

Blessing W, Mohammed M, Ootsuka Y (2012) Heating and eating: brown adipose tissue thermogenesis precedes food ingestion as part of the ultradian basic rest-activity cycle in rats. Physiol Behav 105:966-974.

Blessing WW (2003) Lower brainstem pathways regulating sympathetically mediated changes in cutaneous blood flow. Cell Mol Neurobiol 23:527-538.

Blessing WW (2005) Clozapine increases cutaneous blood flow and reduces sympathetic cutaneous vasomotor alerting responses (SCVARs) in rats: comparison with effects of haloperidol. Psychopharmacology. http://dx.doi.org/10.1007/s00213-0050012-9.

Blessing WW, Nalivaiko E (2000) Regional blood flow and nociceptive stimuli in rabbits: patterning by medullary raphe, not ventrolateral medulla. J Physiol 524(Pt. 1):279-292.

Blessing WW, Li YW, Wesselingh SL (1991) Transneuronal transport of herpes simplex virus from the cervical vagus to brain neurons with axonal inputs to central vagal sensory nuclei in the rat. Neuroscience 42:261-274.

Blessing WW, Arnolda LF, Yu YH (1998) Cutaneous vasoconstriction with alerting stimuli in rabbits reflects a patterned redistribution of cardiac output. Clin Exp Pharmacol Physiol 25:457-460.

Brown MR, Gray TS (1988) Peptide injections into the amygdala of conscious rats: effects on blood pressure, heart rate and plasma catecholamines. Regul Pept 21:95-106. 
Carter RN, Pinnock SB, Herbert J (2004) Does the amygdala modulate adaptation to repeated stress? Neuroscience 126:9-19.

Cox GE, Jordan D, Paton JF, Spyer KM, Wood LM (1987) Cardiovascular and phrenic nerve responses to stimulation of the amygdala central nucleus in the anaesthetized rabbit. J Physiol 389:541-556.

Davis M, Whalen PJ (2001) The amygdala: vigilance and emotion. Mol Psychiatry 6:13-34.

Dayas CV, Day TA (2002) Opposing roles for medial and central amygdala in the initiation of noradrenergic cell responses to a psychological stressor. Eur J Neurosci 15:1712-1718.

Dayas CV, Buller KM, Day TA (1999) Neuroendocrine responses to an emotional stressor: evidence for involvement of the medial but not the central amygdala. Eur J Neurosci 11:2312-2322.

de Menezes RC, Ootsuka Y, Blessing WW (2009) Sympathetic cutaneous vasomotor alerting responses (SCVARs) are associated with hippocampal theta rhythm in non-moving conscious rats. Brain Res 1298:123-130.

Fortaleza EA, Tavares RF, Correa FM (2009) The medial amygdaloid nucleus modulates cardiovascular responses to acute restraint in rats. Neuroscience 159:717-726.

Fox RJ, Sorenson CA (1994) Bilateral lesions of the amygdala attenuate analgesia induced by diverse environmental challenges. Brain Res 648:215-221.

Galeno TM, Van Hoesen GW, Brody MJ (1984) Central amygdaloid nucleus lesion attenuates exaggerated hemodynamic responses to noise stress in the spontaneously hypertensive rat. Brain Res 291:249-259.

Garcia JN, Pedersen NP, Nalivaiko E, Blessing WW (2001) Tail artery blood flow measured by chronically implanted Doppler ultrasonic probes in unrestrained conscious rats. J Neurosci Methods 104:209-213.

Gelsema AJ, McKitrick DJ, Calaresu FR (1987) Cardiovascular responses to chemical and electrical stimulation of amygdala in rats. Am J Physiol 253:R712-R718.

Gozzi A, Jain A, Giovannelli A, Bertollini C, Crestan V, Schwarz AJ, Tsetsenis T, Ragozzino D, Gross CT, Bifone A (2010) A neural switch for active and passive fear. Neuron 67:656-666.

Gray TS, Carney ME, Magnuson DJ (1989) Direct projections from the central amygdaloid nucleus to the hypothalamic paraventricular nucleus: possible role in stress-induced adrenocorticotropin release. Neuroendocrinology 50:433-446.

Herdade KC, Strauss CV, Zangrossi Jr H, Viana MB (2006) Effects of medial amygdala inactivation on a panic-related behavior. Behav Brain Res 172:316-323.

Hilton SM, Zbrozyna AW (1963) Amygdaloid region for defence reactions and its efferent pathway to the brain stem. J Physiol 165:160-173.

Holahan MR, White NM (2004) Intra-amygdala muscimol injections impair freezing and place avoidance in aversive contextual conditioning. Learn Mem 11:436-446.

Iwata J, Chida K, LeDoux JE (1987) Cardiovascular responses elicited by stimulation of neurons in the central amygdaloid nucleus in awake but not anesthetized rats resemble conditioned emotional responses. Brain Res 418:183-188.

Kemble ED, Blanchard DC, Blanchard RJ (1990) Effects of regional amygdaloid lesions on flight and defensive behaviors of wild black rats (Rattus rattus). Physiol Behav 48:1-5.

Kemble ED, Blanchard DC, Blanchard RJ, Takushi R (1984) Taming in wild rats following medial amygdaloid lesions. Physiol Behav 32:131-134.

Kluver H, Bucy PC (1939) Preliminary analysis of functions of the temporal lobes in monkeys. Arch Neurol Psychiatry 42:979-1000.

Kubo T, Okatani H, Nishigori Y, Hagiwara Y, Fukumori R, Goshima Y (2004) Involvement of the medial amygdaloid nucleus in restraint stress-induced pressor responses in rats. Neurosci Lett 354:84-86.

LeDoux JE (2000) Emotion circuits in the brain. Annu Rev Neurosci 23:155-184.

LeDoux JE, Sakaguchi A, Iwata J, Reis DJ (1986) Interruption of projections from the medial geniculate body to an archi-neostriatal field disrupts the classical conditioning of emotional responses to acoustic stimuli. Neuroscience 17:615-627.

LeDoux JE, Iwata J, Cicchetti P, Reis DJ (1988) Different projections of the central amygdaloid nucleus mediate autonomic and behavioral correlates of conditioned fear. J Neurosci 8:2517-2529.

LeDoux JE, Cicchetti P, Xagoraris A, Romanski LM (1990) The lateral amygdaloid nucleus: sensory interface of the amygdala in fear conditioning. J Neurosci 10:1062-1069.

Li Cl, Maglinao TL, Takahashi LK (2004) Medial amygdala modulation of predator odor-induced unconditioned fear in the rat. Behav Neurosci 118:324-332.

Liao W, Qiu C, Gentili C, Walter M, Pan Z, Ding J, Zhang W, Gong Q, Chen $H$ (2010) Altered effective connectivity network of the amygdala in social anxiety disorder: a resting-state FMRI study. PLoS ONE 5:e15238.

Nalivaiko E, Blessing WW (2001) Raphe region mediates changes in cutaneous vascular tone elicited by stimulation of amygdala and hypothalamus in rabbits. Brain Res 891:130-137.

Nalivaiko E, Blessing WW (2002) Potential role of medullary raphespinal neurons in cutaneous vasoconstriction: an in vivo electrophysiological study. J Neurophysiol 87:901-911.

Ootsuka Y, de Menezes RC, Zaretsky DV, Alimoradian A, Hunt J, Stefanidis A, Oldfield BJ, Blessing WW (2009) Brown adipose tissue thermogenesis heats brain and body as part of the braincoordinated ultradian basic rest-activity cycle. Neuroscience 164:849-861.

Pape HC (2010) Petrified or aroused with fear: the central amygdala takes the lead. Neuron 67:527-529.

Pape HC, Pare D (2010) Plastic synaptic networks of the amygdala for the acquisition, expression, and extinction of conditioned fear. Physiol Rev 90:419-463.

Paxinos G, Watson C (1986) The rat brain in stereotaxic coordinates. second ed. North Ryde: Academic Press.

Phelps EA, LeDoux JE (2005) Contributions of the amygdala to emotion processing: from animal models to human behavior. Neuron 48:175-187.

Price JL, Amaral DG (1981) An autoradiographic study of the projections of the central nucleus of the monkey amygdala. J Neurosci 1:1242-1259.

Radley JJ, Sawchenko PE (2011) A common substrate for prefrontal and hippocampal inhibition of the neuroendocrine stress response. J Neurosci 31:9683-9695.

Sah P, Faber ES, Lopez De Armentia M, Power J (2003) The amygdaloid complex: anatomy and physiology. Physiol Rev 83:803-834.

Sananes CB, Campbell BA (1989) Role of the central nucleus of the amygdala in olfactory heart rate conditioning. Behav Neurosci 103:519-525.

Vinkers $\mathrm{CH}$, Bijlsma EY, Houtepen LC, Westphal KG, Veening JG, Groenink L, Olivier B (2010) Medial amygdala lesions differentially influence stress responsivity and sensorimotor gating in rats. Physiol Behav 99:395-401.

Wan FJ, Swerdlow NR (1997) The basolateral amygdala regulates sensorimotor gating of acoustic startle in the rat. Neuroscience 76:715-724.

Watkins LR, Wiertelak EP, Maier SF (1993) The amygdala is necessary for the expression of conditioned but not unconditioned analgesia. Behav Neurosci 107:402-405.

Weiskrantz $L$ (1956) Behavioral changes associated with ablation of the amygdaloid complex in monkeys. J Comp Physiol Psychol 49:381-391.

Werka T, Skar J, Ursin H (1978) Exploration and avoidance in rats with lesions in amygdala and piriform cortex. J Comp Physiol Psychol 92:672-681.

Yu YH, Blessing WW (1997a) Cutaneous vasoconstriction in conscious rabbits during alerting responses detected by hippocampal theta-rhythm. Am J Physiol 272:R208-R216.

Yu YH, Blessing WW (1997b) Acute increases in forebrain blood flow during altering responses in conscious rabbits. Brain Res 767:1-7. 
Yu YH, Blessing WW (1999) Amygdala co-ordinates sudden falls in ear pinna blood flow in response to unconditioned salient stimuli in conscious rabbits. Neuroscience 93:135-141.
Yu YH, Blessing WW (2001) Neurons in amygdala mediate ear pinna vasoconstriction elicited by unconditioned salient stimuli in conscious rabbits. Auton Neurosci 87:236-242.

(Accepted 3 October 2012)

(Available online 13 October 2012) 